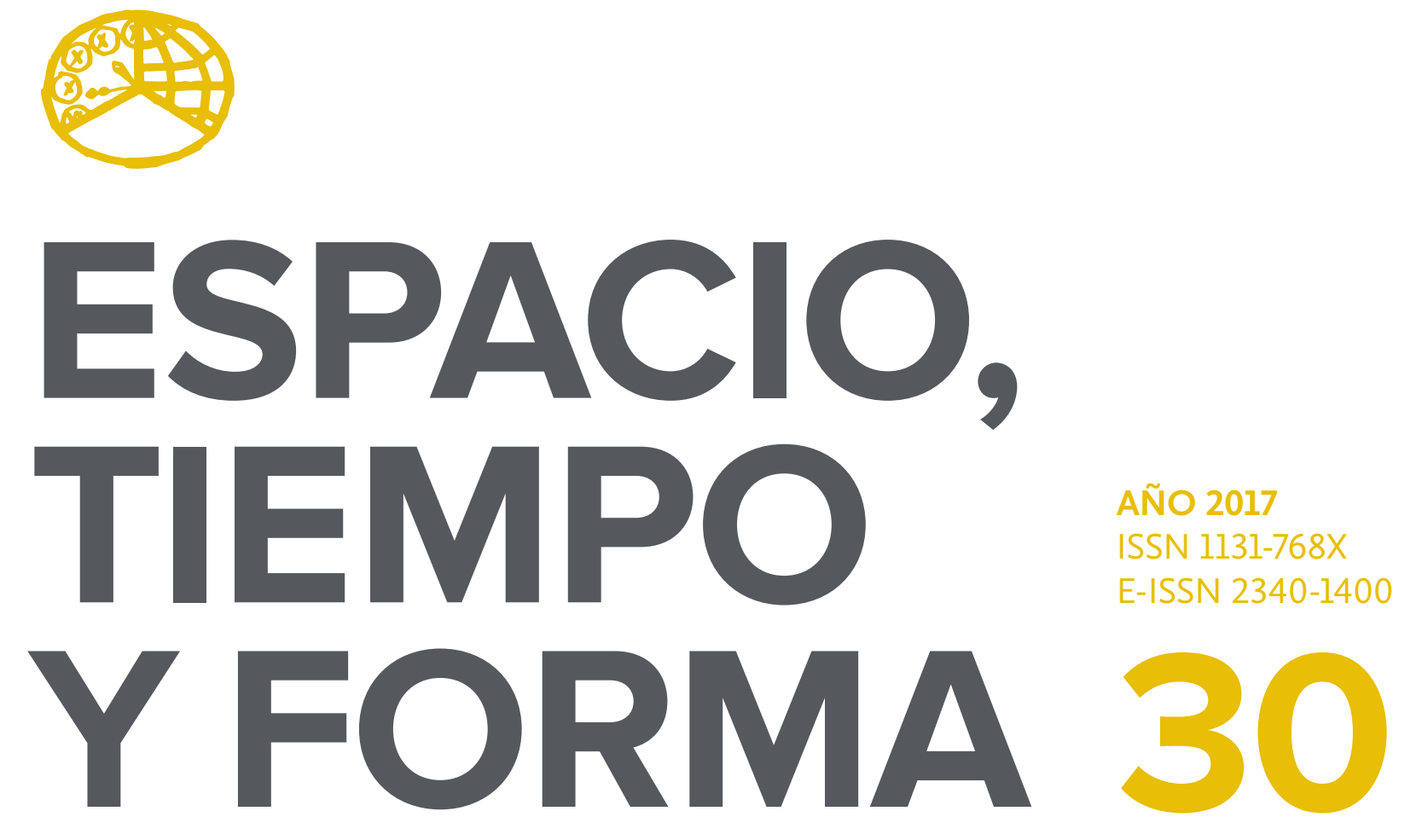

SERIE IV HISTORIA MODERNA

REVISTA DE LA FACULTAD DE GEOGRAFÍA E HISTORIA 


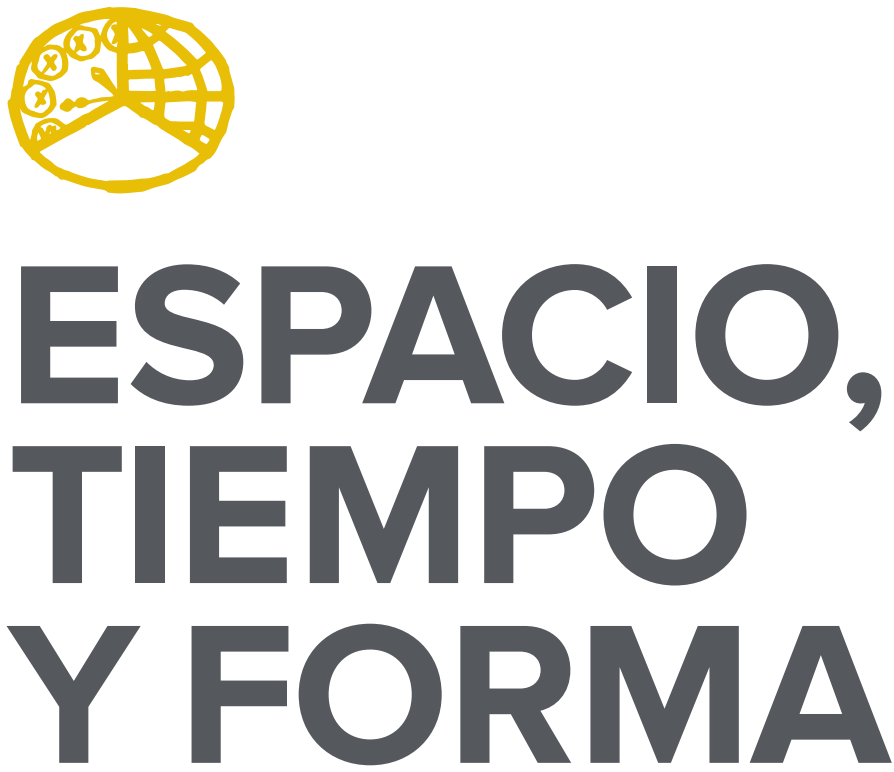

AÑO 2017

ISSN 1131-768X

E-ISSN 2340-1400

SERIE IV HISTORIA MODERNA

REVISTA DE LA FACULTAD DE GEOGRAFÍA E HISTORIA

DOI: http://dx.doi.org/10.5944/etfiv.30.2017

\section{UกED}

UNIVERSIDAD NACIONAL DE EDUCACIÓN A DISTANCIA 
La revista Espacio, Tiempo y Forma (siglas recomendadas: ETF), de la Facultad de Geografía e Historia de la UNED, que inició su publicación el año 1988, está organizada de la siguiente forma:

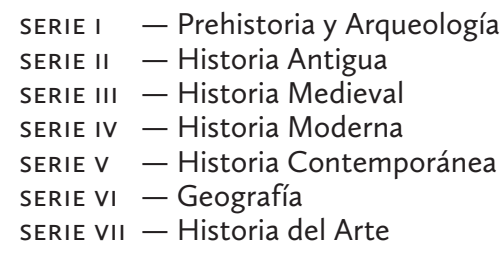

Excepcionalmente, algunos volúmenes del año 1988 atienden a la siguiente numeración:

$$
\begin{aligned}
& \mathrm{N} .^{\circ} 1 \text { - Historia Contemporánea } \\
& \mathrm{N}^{\circ} 2 \text { - Historia del Arte } \\
& \mathrm{N} .^{\circ} 3 \text { - Geografía } \\
& \mathrm{N} .^{\circ} 4 \text { - Historia Moderna }
\end{aligned}
$$

ETF no se solidariza necesariamente con las opiniones expresadas por los autores.

\author{
UNIVERSIDAD NACIONAL DE EDUCACIÓN A DISTANCIA \\ Madrid, 2017 \\ SERIE IV · HISTORIA MODERNA N. ${ }^{\circ} 30,2017$ \\ ISSN $1131-768 X \cdot$ E-ISSN 2340-1400 \\ DEPÓSITO LEGAL \\ $M-21.037-1988$ \\ URL \\ ETF IV · HISTORIA MODERNA · http://revistas.uned.es/index.php/ETFIV \\ DISEÑO Y COMPOSICIÓN \\ Carmen Chincoa Gallardo · http://www.lauridilva.net/cch \\ Impreso en España · Printed in Spain
}

(c) (7) (8) Esta obra está bajo una licencia Creative Commons Reconocimiento-NoComercial 4.0 Internacional. 


\section{MONOGRÁFICO · SPECIAL ISSUE}

LA CONSTRUCCIÓN DE LA HACIENDA HISPÁNICA

(SIGLOS XVII-XIX). EL GOBIERNO DE LA HACIENDA

CONSTRUCTION OF THE $18^{\text {th }}$ - $19^{\text {th }}$ CENTURY SPANISH PUBLIC FINANCE SYSTEM. THE GOVERNANCE OF PUBLIC FINANCES 



\title{
CIFRAS AL SERVICIO DE LA GRANDEZA DEL REY CATÓLICO. LAS FINANZAS DEL IMPERIO VISTAS DESDE EL CONSEJO DE INDIAS A MEDIADOS DEL SIGLO XVII
}

\section{FIGURES IN THE SERVICE OF THE GREATNESS OF THE CATHOLIC KING. THE FINANCES OF THE EMPIRE SEEN FROM THE COUNCIL OF THE INDIES IN THE MIDDLE OF THE SEVENTEENTH CENTURY}

\author{
Guillaume Gaudin \\ Recibido: 15/03/2017 · Aceptado: 13/04/2017 \\ Doi: http://dx.doi.org/10.5944/etfiv.2017.18647
}

\begin{abstract}
Resumen
El carácter «compuesto» de la monarquía hispánica no permite acceder a una visión conjunta de las finanzas reales. Sin embargo, proponemos tratar este problema mediante informaciones procedentes de un personaje secundario, pero bien informado, que trabajaban en las oficinas madrileñas a mediados del siglo XVII: el oficial del Consejo de Indias, Juan Díez de la Calle (1599-I662). Sus memoriales y Noticias Sacras y Reales, contienen una lista de los agentes de la Corona en América, dirigido al Consejo de Indias, y que sirve para disponer de un cuadro (casi) completo de la organización administrativa y contable ultramar. También tenía como destino la Corona, con el objetivo de cifrar el coste de su «masa salarial». El objetivo es doble: demostrar la justa posesión del Nuevo Mundo presentando los gastos importantes de la Corona y seguir vigilante en lo que se refiere a la situación crítica de la Real Hacienda.
\end{abstract}

Palabras clave

Hacienda real; Consejo de Indias; listas; coste; Carrera de Indias.

\section{Abstract}

The «composite» form of the Hispanic monarchy does not allow access to an overall view of royal finances. However, we propose to deal with this problem through information taken from a secondary but well-informed character of the Madrid offices in the mid-seventeenth century: the clerk of the Council of the Indies,

1. Framespa, Université de Toulouse, CNRS, Toulouse, France. Correo electrónico: guillaume.gaudin@univ-t/se2.fr Traducción: Esther Bougeard. 
Juan Díez de la Calle (1599-I662). His memoirs and Noticias Sacras y Reales are a list of royal agents in America: it is, for the Council of the Indies, the opportunity to have an (almost) complete picture of the administrative organization overseas. It is also, for the Crown, a way of assessing the cost of its «wage bill». The goal has two purposes: to demonstrate the just titles over the New World by presenting the important expenses of the Crown and to remain vigilant of the critical situation of the Royal Treasury.

\section{Keywords}

Royal Treasury; Council of the Indies; lists; wages; Carrera de Indias. 
«Porque si bien los Reyes son obligados a mirar por [la Hacienda real] como por la sangre del cuerpo místico de sus estados, esto ha de ser sin prejuicio de la reputación de ellos».

Juan Grau y Monfalcón, procurador general de las islas Filipinas en la Corte, $\mathrm{I} 637^{2}$.

\section{INTRODUCCIÓN}

La unión de las coronas de Castilla y Aragón, la asociación del Sacro Imperio y de los reinos ibéricos, así como la formidable expansión territorial de la Monarquía católica en América desde finales del siglo XVI, impulsaron a los modestos reyes hispánicos medievales a la cabeza de un imperio planetario. Los tesoros americanos financiaron en gran parte la empresa imperial fundamentada en la política militar. Sin embargo, el carácter «compuesto» de la monarquía hispánica, o sea su división en varias entidades políticas más o menos autónomas, limita una visión conjunta de las finanzas reales³. A pesar de la creación de un Consejo de Hacienda, que completaba el carácter polisinodal de la monarquía española, no existe una caja central sino una gestión compartimentada de cada reino. Cabe añadir que las especificidades objetivas de los reinos americanos (distancia, escala continental, riquezas inconmensurables) y de sus finanzas constituían un reto para la Corona: ¿Cómo organizar y registrar las finanzas a distancia? ¿Cómo conocer los beneficios y los costes del imperio? ¿En la época, se justifica la pregunta? En caso afirmativo, ¿en qué términos?

Es difícil contestar a estas preguntas de manera global. Las cantidades de oro y plata que llegaban a Sevilla y su impacto en las economías y las finanzas hispánicas y europeas han suscitado, desde hace mucho tiempo, numerosas e importantes obras: incluso con las herramientas modernas de cálculo, resulta muy complicado medir los flujos comerciales atlánticos y su impacto sobre los precios (Hamilton, Chaunu, Morineau, etc.). Más recientemente se ha cuestionado esta temática económica desde puntos de vista más sociales y políticos: las investigaciones más innovadoras han tratado de relacionar la política imperial de la monarquía católica con el comercio atlántico. Así Carlos Álvarez Nogal trabajó sobre el impacto de la política fiscal de la Corona sobre la economía atlántica, mientras que José Manuel Díaz Blanco estudió en la misma perspectiva la estrecha implicación de los cargadores a Indias a la política fiscal desde Felipe II hasta Carlos II ${ }^{4}$. Ambiciosos estudios han abordado estas cuestiones de manera global, aunque el tema ofrece todavía numerosas posibilidades 5 .

2. Grau y Monfalcón, 1865: 371-372.

3. A pesar de las reformas borbónicas de la Nueva Planta «habrá que esperar las reformas de Bravo Murillo, e 1849-1851, para que se establezca de manera perenne un «presupuesto general del Estado» único y un Tesorero público único», DUBET, 2010: 188.

4. Álvarez Nogal, 1997 y 2000 y Díaz Blanco, 2012.

5. Yun Casalilla, 2004. Bernal Rodríguez, 2005. 
Proponemos, pues, tratar este problema desde la historia de las representaciones y de la cultura política mediante informaciones procedentes de un personaje secundario, pero bien informado, de las oficinas madrileñas a mediados del siglo XVII. El oficial del Consejo de Indias, Juan Díez de la Calle (I599-I662) era, efectivamente, un buen conocedor y un observador meticuloso de la administración de las Indias occidentales ${ }^{6}$. Sus memoriales y Noticias Sacras y Reales, publicados en formas diversas en los años I640 son una lista de los agentes de la Corona en América: es, para el Consejo de Indias, la oportunidad y la forma de disponer de un cuadro (casi) completo de la organización administrativa y contable ultramar. Es también, para la Corona, una manera de cifrar el coste de la «masa salarial» de los agentes reales (civiles, militares y eclesiásticos). La meta tiene dos finalidades: demostrar la justa posesión del Nuevo Mundo presentando los gastos importantes de la Corona y seguir vigilante en lo que se refiere a la situación crítica de la Hacienda real. Cabe señalar que Diez de la Calle escribe en un contexto intelectual particular: fue contemporáneo y colega (aunque subalterno) de los más eminentes autores, tanto juristas como historiadores, sobre las Indias Occidentales. La influencia de personajes como Antonio de León Pinelo, Juan Solórzano Perreira o, en cierta medida, el cronista de Indias Gil González Dávila, es central para entender el pensamiento y las representaciones del oficial del Consejo de Indias?.

En efecto, la situación financiera de la Monarquía católica en este fin de Siglo de Oro es bastante delicada: la política hegemónica tiene un gasto desorbitado que lleva a tomar decisiones fuertes como la suspensión de pago de $1645^{8}$, cuando las diferentes sublevaciones cuestionan el modelo imperial hispánico9. Más allá de la coyuntura, conviene recordar que el periodo que consideramos es él de la preestadística, antes de la contabilidad pública, en vísperas de la aritmética política inglesa y la statistik alemana que aparecieron en la segunda mitad del siglo XVII. Existe sin embargo la necesidad de conocer sus reinos para administrarlos mejor, pero esta necesidad no se expresa por un «conjunto de rutinas administrativas» ${ }^{\mathrm{IO}}$, sino por un conjunto heterogéneo de los saberes ${ }^{\mathrm{II}}$.

Díez de la Calle no es un experto en la ciencia de las cuentas ${ }^{12}$, pero da importancia a captar en su conjunto («reducir») por lo menos enumerar, inventariar las Indias Occidentales. Principalmente administrativas, pero igualmente políticas, sus preocupaciones son presentar la grandeza y la desmesura de la monarquía: cifras hiperbólicas, a veces poco realistas, se mezclan con otras muy precisas. Captar el

. GAUDIN, 2013.

7. León Pinelo, 1953; Millares Carlo, 1961; García Hernán, 2007.

8. SANZ AYÁN, 2013.

9. PARKER, 2006.

10. Desrosières, $2010: 26$

11. BRENDECKE, 2012

12. El Consejo de Indias, creado en 1524, dispone de un oficial de Cuentas desde 1528, y la nueva misión de control de cuentas (1542) que depende del Consejo da origen a la Contaduría Mayor de Cuentas. Véase Recopilación de Leyes de Indias, Libro II, Titulo XI. Sus funciones son amplias. 1. Cuentas propias del Consejo (cuentas de receptor de penas, salarios del Consejo), control de las cuentas de la Casa de Contratación y de los oficiales de Indias. 2. Envío de contadores de cuentas en las Indias y visitas. 3. Gastos extraordinarios del Rey en las Indias. Véase SÁNCHEZ BELLA, 1968: 92-95. 
conjunto, queda complicado porque tiene a su disposición informaciones incompletas en el tiempo y en el espacio. Por lo tanto, ¿qué formas y qué grado de conocimiento tienen los miembros del Consejo de Indias en Madrid de los ingresos y gastos de la Corona en las Indias Occidentales? Pregunta que se comprende en un periodo en que el poder no dispone todavía de las herramientas de la estadística descriptiva en el contexto de un imperio extenso.

\section{EL COSTE DEL IMPERIO ESPAÑOL EN LAS INDIAS OCCIDENTALES: ENTRE ENUMERACIÓN Y CUANTIFICACIÓN}

Con la enumeración de los agentes de la Corona en América, estamos en el corazón del proyecto de Diez de la Calle. Entonces, es natural que el autor culmine en precisión para censar el conjunto de los agentes de la Corona en las Indias. La representación del espacio americano está hecha de ciudades y de instituciones, pero quizás sobretodo de hombres, más particularmente los que son remunerados, nombrados y administrados por el rey. Ahora bien, el nombramiento o la creación de un oficio es una decisión no financiera que tiene un impacto en las finanzas ${ }^{13}$. lgualmente conviene tomar en cuenta la dimensión política y simbólica en una administración que todavía está lejos de ser una burocracia moderna: la autoridad y el prestigio de los agentes de la Corona se fundamentan en efecto en su nombramiento por el rey o por uno de sus representantes. De diferentes maneras, un lazo directo se establece entre el monarca y su «empleado»: el juramento, la retribución, la delegación de poder (generalmente jurisdiccional), la pertenencia a la Casa del rey en el contexto de un imperio planetario, estas muestras de fidelidad tienen su importancia.

Además, el origen de las listas más o menos completas de los oficios reales se debe a la decisión de introducir una nueva tasa en toda la monarquía, la de la media anata $^{14}$ (decreto real del 9 de agosto de I63I). Efectivamente, en I63I, León Pinelo establece una lista y una cuenta -que Diez de la Calle completa hasta I648- de todos los oficios en las Indias occidentales ${ }^{15}$. La totalidad es de 4797: incluye 178 oficios en España, 2.767 en Perú y i.853 en Nueva España. Finalmente, basándose en los datos de León Pinelo y Díez de la Calle, el historiador es capaz de contar alrededor de I6.500 agentes que servirían a la Corona en las Indias occidentales en la primera mitad del siglo XVII: 5.000 civiles, 6.000 militares, 3.000 marinos y 2.500 eclesiásticos ${ }^{16}$.

13. Dubet, 2010: 190.

14. Tasa creada en 1631 sobre la concesión o la sucesión de cargas reales. Antes de acceder a sus cargos, los oficiales debían pagar una cantidad correspondiente a un tercio de su salario anual.

15. Biblioteca Nacional de España (BNE), Ms 3048, ff. 101-162: «Relación de los oficios, cargos de gobierno, justicia, hacienda, guerra y mar (...) que su Majestad provee por su Real Consejo de Indias. 1631. por el licenciado Antonio de León Pinelo». Díez de la CALLE, 1645. En Portugal se halla un documento comparable, el Livro das avalliações de todos os officios do Reyno de Portugal. Anno 1640, véase HesPanha, 1989: 43-44.

16. Berthe \& CALVO, 2011: 73. 
Los errores son relativamente mínimos. En efecto, en toda la relación, León Pinelo se había esforzado en anotar el número de oficios en el margen a fin de facilitar las sumas finales pero el rigor y la sistematización no eran oportunos y varios subtotales presentan operaciones erróneas (principalmente en el virreinato de Perú). A pesar de las preocupaciones que tomaron nuestros aprendices en estadísticas del siglo XVII para no contar dos veces los mismos oficios, las diferencias entre sus datos y los del historiador subsisten ${ }^{17}$ anta la falta de rigor y de precisión alrededor de algunos cálculos y datos brutos, podemos notar que Díez de la Calle profundizando las investigaciones, añade hasta 300 oficios a la Relación universal. Por otra parte, León Pinelo se aparta, algunas veces, de los límites que se había fijado. Por ejemplo, añadiendo y luego sustrayendo el personal de la Carrera de Indias. Estos procedimientos atestiguan de modalidades de trabajo y de objetivos que dependen más de la enumeración que de la cuantificación.

A pesar de la aproximación de los datos, no cabe duda que estamos en presencia de un documento excepcional desde el punto de vista de la ciencia administrativa: el Consejo de Indias y por consiguiente el rey conocen ahora el número de representantes reales en las Indias occidentales, así como el coste salarial de este conjunto.

La preocupación de conseguir resultados globales sirve de base a otra operación que consiste en calcular la «masa salarial» en las Indias, las rentas procedentes de los oficios vendibles y por fin el importe de las encomiendas. Este término actual de «masa salarial» a pesar de ser anacrónico permite mostrar el interés del Consejo en calcular el coste que representa el conjunto de los salarios pagados a las Indias. Se debe la iniciativa de esta operación a León Pinelo en su Relación de i63I, y Diez de la Calle la completa actualizándola ${ }^{18}$.

CUADRO 1: LA MASA SALARIAL SEGÚN LEÓN PINELO Y DÍEZ DE LA CALLE

León Pinelo (1631) Díez de la Calle (1648)

Salarios de los oficios proveídos por el rey $\quad 575.197$ ducados 771.738 ducados

Salarios de los oficios proveídos por otros $\quad 369.483$ ducados $\quad 369.483$ ducados ministros

\begin{tabular}{|c|c|c|}
\hline Salarios de la gente de guerra & 1.480 .499 ducados & 1.163 .636 ducados \\
\hline Total & 2.425.179 ducados & 2.304 .857 ducados \\
\hline Oficios venales & 4.172 .238 ducados & 4.172 .238 ducados \\
\hline Encomiendas & 932.228 ducados & «Cerca de un millón» \\
\hline
\end{tabular}

Díez de la Calle se esforzó en actualizar la rúbrica en la que es más preciso, los oficios provistos directamente por el rey y la Cámara de Indias: la diferencia es sustancial con cerca de 200.000 ducados suplementarios ${ }^{19}$. Es una forma de mostrar el

17. Ibíd.: 70.

18. Díez de la CaLle, 1648.

19. Se explica por los puestos creados entre 1631 y 1648 pero también por los puestos procedentes de un censo más preciso de Díez de la Calle. 
poder del rey y del Consejo. Estos últimos controlan 6r\% de la masa salarial según León Pinelo y 68\% según Díez de la Calle cuando sólo nombran una minoría de oficiales: por consiguiente, los cargos más altos, los mejor renumerados, están en la mano del monarca. El agente no se toma la misma molestia con los oficios provistos por las autoridades locales y reproduce tal cual el resultado de León Pinelo. En lo que se refiere a los saldos de los empleos militares, prefiere dar la cantidad redondeada y aproximativa, en otra unidad monetaria (el peso que equivale a 0,73 ducado) quizás para inflar las cifras. Los datos adjuntos referentes a los oficios venales y las encomiendas corresponden a ingresos específicos que se asociaban entonces para mostrar así la importancia de la gracia real.

Son de naturalezas diferentes ya que no tienen un ritmo anual, pero atestiguan las destrezas utilizadas por la Corona para sacar otros provechos o hacer ahorros. En cuanto al reparto podemos seguir a Jean-Pierre Berthe y Thomas Calvo que indican que los salarios de los agentes de la Corona representan entre 4I y 54\% de los gastos de la Monarquía en las Indias (34\% de los ingresos), y esto sin contar los gastos ligados al Patronazgo real. Sin embargo, el agente no alcanza este resultado estadístico global; no es por falta de capacidad, pues las operaciones no son complicadas, sino quizás porque los resultados perjudicarían las declaraciones del agente ${ }^{20}$. Efectivamente, las cifras tienen un valor didáctico para Díez de la Calle que desea demostrar al lector la grandeza de la Monarquía católica, la mansedumbre del rey y su voluntad de garantizar un buen gobierno a sus súbditos.

\section{CONTAR LOS TESOROS AMERICANOS: UN PATCHWORK DE DATOS}

Díez de la Calle se revela muy preciso y exhaustivo cuando tiene que tratar de las actividades mineras, corazón de la economía colonial. Los metales preciosos van destinados a España y al financiamiento de la política imperial: representan el cargamento principal de la Carrera de Indias. Además, la divulgación de las riquezas americanas sirve al rey de España, principalmente en tiempos de guerra cuando los sueldos de las tropas dependen de la suerte de la Carrera y los acreedores llaman a la puerta del Rey Católico ${ }^{21}$.

Las minas son pues, al lado de las ciudades, los puntos que constituyen la red territorial hispánica como lo muestra una lista de las veintiocho «minas de oro y de plata de Perú» para la que Díez reserva el último capítulo del libro sobre la audiencia de Lima ${ }^{22}$. Regiones mineras se destacan claramente de las Noticias Sacras y Reales como la Nueva Galicia «tierra riquísima de metales de plata»"23, la Nueva Vizcaya o Tegucigalpa. El yacimiento de Zacatecas fue descubierto el «día de la natividad de

20. Demuestran que en los años 1621-1640, el saldo de ingresos y gastos de la Hacienda real en América es ampliamente positivo a pesar del coste elevado de la administración. BERTHE \& CALVO, 2011: 75-77.

21. MORINEAU, 1984: 46-47.

22. BNE, Ms 3024, f. 139.

23. Ibid.: f. 94 
Nuestra Señora», una señal providencial para indicar «las minas de plata más ricas de Nueva España» ${ }^{24}$. Los frentes pioneros del siglo XVIl son portadores de esperanza como Nuevo México o Nuevo León «que abundan de metales y donde 220 minas se han descubierto en poco tiempo.» ${ }^{25}$ Díez de la Calle es el relevo de los estímulos de la Corona para el desarrollo de la actividad minera garante de las finanzas reales.

Potosí ocupa naturalmente un lugar importante en las Noticias como otras descripciones y crónicas de la época. La extracción de plata de esas minas pertenece al discurso hiperbólico de Díez de la Calle: «Esta montaña ha enriquecido Europa, África y Asia», «su vigor parece inalterable y sin límite» ${ }^{26}$. Le reserva una subparte de su Memorial y Compendio breve en la que puede enumerar cifras astronómicas: los ingresos de los mineros en un año ascienden a 3.851.250 pesos ensayados, el quinto real alcanza un millón de plata y 4.000 españoles y 50.000 indios trabajan en ello ${ }^{27}$. Díez citando a Claudio Clemente refiere que entre I545 y i642, 3.000 millones de ducados a once reales de plata se han extraído de Potosíi ${ }^{28}$. Se inscribe en un linaje de autores que trata de valorar la producción de Potosí tal como Solórzano Pereira, citando varios autores (Herrera, Acosta), que habla de III millones de pesos ensayados entre 1543 y 1585 .

En lo que se refiere a las minas de Oruro, Díez de la Calle se lanza hace un resumen que debe determinar los beneficios que saca la Corona de la creación de la mina en I606 hasta i6ı。. Es capaz de dar los ingresos del quinto real y los depósitos de plata pertenecientes al rey de i606 a I6Io, las tasas sobre el mercurio y la alcabala por un periodo indeterminado, los ingresos sacados de la venta de los oficios en I606 y del arrendamiento de las minas por 4 años $^{29}$. La suma de estas cifras lleva a «los beneficios de las finanzas reales de un millón 309.973 pesos ensayados de 450 maravedís cada uno.» No se sabe nada de la producción de la mina después de i6ro.

Para la Corona, el mercurio es de una importancia crucial porque, no sólo es imprescindible en la producción minera argentífera, sino que, con el monopolio de Estado que lo enmarca, permite afirmar igualmente la intromisión de la Corona en esta producción. Díez de la Calle expresa su interés en la venta del mercurio chino que, vía las Filipinas, va destinado a las minas de Nueva España ${ }^{30}$. Principalmente consagra un epígrafe al «azogue que se remite de España a las Indias, la cantidad que es necesaria, y lo que importa tenerlo con tiempo en Méjico. $»^{31}$ Se trata de una lista precisa de las llegadas de mercurio a Nueva España desde España de I624 a I653 (con lagunas) y de su reparto entre las diferentes minas. No obstante, las minas de Huancavelica no logran un tratamiento extraordinario en las Noticias: desde luego se comprende que se trata de un lugar importante con sus 300 castellanos

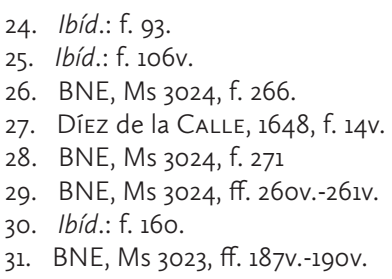


$\mathrm{y}$ «muchos indios», pero no se dice nada de su papel crucial en la producción de Potosís $^{32}$. Este modesto lugar se explica sin duda por la crisis que conoce el lugar durante la primera mitad del siglo XVII y la preferencia concedida al mercurio español en la Noticias y en los hechos.

Diferentes rúbricas tratadas por Díez de la Calle explican asimismo al lector el funcionamiento financiero del imperio español, no de manera sintética sino a lo largo de la lectura. Díez se muestra a veces didáctico como a propósito de la Caja real de Guadalajara dando la lista de todos los ingresos fiscales:

«En la caja Real de la Ciudad de Guadalajara de la Provincia de la Nueva Galicia, entran por Hacienda Real los quintos Reales de la plata, diezmos, Tributos de tomines, nuevo servicio, maíces, y gallinas, alcabalas, novenos. oficios vendibles, renunciables y mercedes, de tierras, derechos de mulatos, y negros libres, procedido de far [sic.], tributos de Indios laboríos, penas de Cámara, procedido de azogues, donativos, composiciones de extranjeros, Mesada eclesiástica para ayuda a las guerras, los tomines, maíz, y gallinas, que pagan los Indios de los pueblos de su Majestad, y encomenderos, media anata antigua, y nueva, manifestaciones de plata de las minas Hostotiquepaque, Yzatlan, Xocotlan, Guachinango, Ocotitlan, Tinamache, Xora, Mezquitlan, y las demás de aquel Reino, que se han referido (...)»33.

Este abanico de descuentos en especie y en efectivo demuestra una fiscalidad de Antiguo Régimen «en los trópicos»: junto a las tasas sobre el maíz pagadas en tomines se encuentran los dos pilares de la autoridad colonial en América, es decir, el tributo indígena y la encomienda.

A pesar de la decisión de suprimirlas en I542, las encomiendas existentes habían sido mantenidas y prolongadas. Están muy presentes en la obra de Díez de la Calle. En Yucatán se trata implícitamente de la supresión de las encomiendas «conforme a las Leyes Nuevas» ya que la Caja real percibe los tributos de los indios para repartirlos entre los Conquistadores (que no tuvieron repartimientos). La mayoría de los corregidores de la audiencia de Lima nombrados por el virrey recibe una paga en «pesos ensayados de indios que son i2 reales y medio (...) y que llaman ensayados de tasas» ${ }^{34}$. Este desliz semántico se explica por el paso difícil de la encomienda que se debe en servicio personal a la que se debe en plata o en especie. Con el fin de eliminar el servicio personal y sus abusos, los oidores debían tasar a los indios, es decir organizar una visita con el objeto de contabilizar la población indígena de los pueblos y de calcular lo que cada indio tributario debería pagar cada año ${ }^{35}$. En el lugar mismo, particularmente en las regiones alejadas de la sede de las audiencias y en las que los encomenderos seguían poderosos, la realización de este dispositivo se reveló particularmente larga y difícil. En la última parte de las Noticias Sacras, una copia de la cédula del I ${ }^{\circ}$ de febrero de 1648 recuerda la importancia de conocer «el número de indios de cada una [de las audiencias], qué tributos pagan,

32. BNE, Ms 3024, ff. 118v.-119.

33. Díez de la CALLe, 1648 , f. 112 r.

34. BNE, Ms 3024, ff. 89-90v.

35. ZAVALA, 1978-1980. 
en qué forma» e invita a seguir esta política de tasación ${ }^{36}$. Los envites consisten igualmente en aplicar la media anata a las encomiendas y confirmar los títulos de los encomenderos.

Así, las encomiendas se presentan claramente como una forma de renta para la Corona en el cuadro general presentado más arriba que indica I.00o.ooo de ducados en encomiendas para el año I648. Díez expone en detalle las autoridades capaces de encomendar y el valor de las encomiendas en una lista de cuatro páginas: en totalidad las encomiendas representan 942.00o pesos (514.00o para Perú y 428.000 para Nueva España) ${ }^{37}$. Vemos que el virrey de Nueva España no tiene esta facultad de encomendar y que la situación en Florida, en Nuevo México o en Nuevo León no permite establecer las encomiendas. Díez da el importe de todos los tributos de Yucatán para I645, I54.275 pesos, y también algunos gastos como una parte del sueldo del capitán de artillería de Mérida ${ }^{3}$. Además, varias gracias reales se pagan «en renta en indios», en encomienda (o su prolongación) como con la familia del adelantado de Nueva Galicia ${ }^{39}$ o en peso ensayado de indios o de tasa como los corregidores de la audiencia de Lima. La limosna de vino y aceite de los conventos se paga en encomiendas ${ }^{40}$. La casa de aposento de los miembros del Consejo de Indias se paga en vacaciones de encomiendas ${ }^{41}$.

Díez de la Calle expone igualmente el tema de la financiación de algunas gracias reales con recursos específicos. Menciona las mercedes pagadas en indios y también «las quitas y vacaciones de Nueva España, un género de hacienda que Su Majestad ha acostumbrado a hacer merced a algunas personas» ${ }^{42}$. Se saca la quita del salario de los alcaldes mayores y corregidores provistos por el virrey y representa un cuarto de este salario.

Con el Patronato real, las relaciones entre la Iglesia y la Hacienda real ocupaban igualmente una gran importancia para la Corona. Como suele hacerlo Juan Díez de la Calle coge la pluma para explicar de manera sencilla el funcionamiento de las grandes instituciones. A partir del Memorial informatorio de I645, redacta en dos páginas una nota sobre la forma del reparto de los diezmos de los obispados ${ }^{43}$. Se explica en las Noticias el recobro del diezmo del arzobispado de Méjico: dos jueces hacedores se hacen cargo de administrarlo. Díez dispone de un informe del arzobispo fechado de 1646 que afirma que la «toda la renta de arzobispo, prebendas, y novenos llega a 63.629 pesos al año». La cuarta arzobispal caría en función de los años alrededor de 20.000 pesos, es algo más elevada que la de los obispos de Cádiz o de Oviedo (I6.50o), pero se sitúa lejos detrás de Sevilla (I37.500)ㄴ․ El arzobispo

36. Ibíd.: ff. 379-387.

37. BNE, Ms 3024, ff. 91-92v. «De los virreyes y gobernadores que tienen facultad de Su Majestad para encomendar los Indios de su districtos y valor de las encomiendas» y DíEZ DE LA CALLE, 1646, f. 183.

38. BNE, Ms 3024, ff. 87V.-88.

39. Ibíd.: f. 90.

40. Ibíd.: ff. 384V.-387.

41. Díez de la Calle, 1645, f. 24 V.

42. Díez de la CaLle, 1646, f. 179.

43. Díez de la CALLe, 1645, f. 14, «Del que vale la gruesa dellos 16.000 pesos al año». Reproducido en: BNE, Ms 3023, ff. 129V.-131V.

44. BNE, Ms 3023, ff. 127V.-128. 
de Lima está mucho mejor dotado con 68.750 pesos de renta mientras que el de Santa Fe de Bogotá recibe $19.250^{45}$. La renta de La Plata con la presencia de Potosí, asciende a 82.500 pesos al año. Algunas diócesis no alcanzan 2.00o pesos como en Buenos Aires, La Imperial, San Juan de Porto Rico y los tres obispados de las Filipinas.

El diezmo debido a las masas monetarias que arrastra y al Patronazgo real, se inscribe claramente en las preocupaciones del oficial del Consejo de Indias. No puede ignorar las tensiones que rodean su recaudación acerca de las órdenes religiosas, especialmente los jesuitas, pero nada se transparenta de esta problemática ${ }^{46}$. Una excepción sin embargo aparece al final del manuscrito de las Noticias donde se encuentra una sentencia impresa del Consejo de Indias del i6 de junio de i657. Esta condena obligaba las órdenes dominicana, agustina, mercedaria y jesuita a pagar el diezmo al rey para que se entregue después a los obispados ${ }^{47}$. Sea lo que fuere la obra de Díez de la Calle recuerda constantemente el entrelazamiento entre los poderes temporal y religioso.

\section{LA CARRERA DE INDIAS: UN ACERCAMIENTO A LOS TESOROS LLEGADOS A SEVILLA}

Se revela asimismo que Díez de la Calle fue un observador de los cargamentos de metales preciosos procedentes de América, prueba de la extrema vigilancia del Consejo de Indias en lo que se refiere a la Carrera de Indias por deseo de evitar el fraude y de garantizar las finanzas de la monarquía. La producción y la disponibilidad de metales preciosos están, desde el principio, al centro de las preocupaciones de la Corona: las informaciones sobre este tema gozan de un trato privilegiado. Desde I494, en una Orden real del 7 de junio, Bernal Díaz de Pisa establece en la Española, el primer sistema de control contable del oro, y se establece en I5Io un sistema de registro de las remesas. Antonio Miguel Bernal explica cómo funciona esta red de comunicación y el secreto que la rodea ${ }^{4}$. En cuanto un agente de la Corona o un conquistador estaba en posesión de un nuevo informe sobre las minas o el transporte de metales hacia España debía informar la Casa de la Contratación de Sevilla. Desde 1509 se establece que la comunicación de informaciones sobre este tema debe permanecer secreta y efectuarse en lenguaje codificado. La Corona instaura progresivamente un proceso contable con el fin de controlar desde la mina hasta Sevilla la producción, la transformación, la marca y el transporte de los metales preciosos: los registros de Sevilla encierran toda la información contable de las entradas y salidas de mercancías y metales.

En efecto, uno de estos documentos presenta la contabilidad de las llegadas entre I62I y I648 y sirvió al historiador Michel Morineau para efectuar cotejos

45. Díez de la Calle, 1645, ff. 22-23v.

46. Sobre este tema véase, MAZín 2014.

47. BNE, Ms 3024, ff. 426-427.

48. Bernal Rodríguez, 2005: 283-284. 
con las cifras indicadas por las gacetas holandesas ${ }^{49}$ : Relación de lo que monta la plata, oro y reales que para su Majestad y particulares se ha traído de las Indias en las Armadas y flotas que han llegado a estos reinos desde el año de I62I hasta el de I645 en esta manera ${ }^{50}$. Según Morineau los datos de Díez de la Calle no difieran mucho de los de las gacetas holandeses: prueba del buen nivel de información del oficial ${ }^{51}$. Las relaciones de la Casa de la Contratación son documentos realizados a partir de los libros de registro de los buques con el fin de informar rápidamente el rey del valor de los metales preciosos que llegaron con la flota. En realidad, se redactaban dos tipos de documentos: un inventario por buque, con la suma y su propietario y la relación sumaria general, un resumen de estos inventarios en el que aparece el volumen total de los capitales registrados por una flota. Se copiaban estos dos documentos en tres ejemplares para el Consejo de las Indias, Consejo de Hacienda y para la Casa de la Contratación ${ }^{52}$. Los valores proporcionados son bastante exactos y Díez de la Calle dispone así de una síntesis que va de i62I a i648 es decir desde el principio del reinado de Felipe IV hasta la actualización del documento. Esta relación de cuatro folios, inserta en un borrador del Memorial y Noticias Sacras y Reales (I646), no fue finalmente publicada. No obstante, ofrece la visión de que dispone el Consejo de Indias sobre la llegada de los metales preciosos.

Para esos 27 años, se dispone de una entrada por flota que llega y, en el margen, las naos en que no llegaron flotas. Cada entrada indica el nombre del general de la flota, y él de la flota de la Nueva España y a menudo el mes de llegada que no corresponde siempre al año de envío... (en I64I, I643, I645, dos convoyes llegan el mismo año). Luego se diferencian las cantidades que corresponde a «Su Majestad» de las de los «particulares» y se calcula la totalidad en maravedíes y después en ducados. En las siete primeras páginas del documento, se indica a la derecha la totalidad acumulada y se anota arriba en la página siguiente; este recuento no se hace hasta el final, prueba que el documento no se ha hecho de una vez. Hacia la mitad del informe, se hace un primer balance: «Monta lo venido para Su Majestad y particulares desde el año de I62I hasta fin de I636, noventa millones, veinte y cinco mil seiscientos y cuatro ducados de a 375 maravedíes». Por otra parte, los importes de los dos últimos años, I647 y I648, se cifran en pesos y no en maravedíes. Otro elemento que muestra que el rigor del documento se va embotando, para I64I Díez adiciona el añil y los «frutos» al oro y a la plata antes de hacer la suma total"53. Por fin Díez de la Calle anota en el margen al final que la totalidad de las llegadas corresponde a más de I20 millones de ducados. Esta cifra incluye probablemente los cuatro millones de ducados perdidos con la toma de la flota por los holandeses en I628 en la bahía de las Matanzas. La lista presenta un cuadro más bien triste con una baja fuerte y constante de las llegadas de metales preciosos: algo ya destacado por Hamilton, Chaunu y aún más precisamente Morineau. Durante los años I62I-I645,

9. MORINEAU, 1984: 42-119.

O. BNE, Ms 3010, ff. 190-193V.

1. MORINEAU, 1984: 63

2. Álvarez Nogal, 1998: 453-488.

3. MORINEAU, 1984: 106 . 
no es una «coyuntura económica» sino el «peso de los acontecimientos»-más un aumento del fraude- que explica los inicios del «declive» tanto debatido, porque en América el cargamento de metales nunca disminuyó ${ }^{4}$.

Frente al secreto acerca de los tesoros, un poco de publicidad sobre la riqueza de España y su aptitud para pagar sus deudas no era malo para la Hacienda real. Por eso, en el Memorial informatorio, Díez no duda en publicar las cuentas más recientes del año I645, año muy satisfactorio del decenio: «Para Su Majestad (que Dios guarde) en barras, oro, reales y plata I millón 582357 pesos; Para Particulares en lo mismo, 648526 pesos; en frutos, 799574 pesos; Que todo monta 3 millones 30457 pesos de a ocho reales» ${ }^{55}$. Curiosamente estas cifras no corresponden en absoluto a la Relación manuscrita de Díez de la Calle:

«Flota de Nueva España que llegó a cargo de d. Martin Carlos de Mencos en agosto de $1645=$ a 7 de agosto. Su Majestad 293006662 [maravedíes $=1077230$ pesos] Particulares 288886304 [maravedíes $=1062082$ pesos] [Total] 581892966 [maravedíes $=$ 2139312 pesos]»

En realidad, la diferencia se debe a que se refieren a dos fuentes diferentes: la primera estimación elevada parece proceder de la carta del 7 de agosto de I645 enviada al rey por el general Carlos de Mencos a su llegada, mientras que la segunda estimación baja corresponde exactamente a las cifras que dieron los oficiales de la Casa de la Contratación en una carta del 23 de agosto de I $645^{57}$.

\begin{tabular}{|lcc}
\hline [en maravedíes] & $\begin{array}{c}\text { Carta del 7 de agosto de 1645 } \\
\text { del general Carlos de Mencos }\end{array}$ & $\begin{array}{c}\text { Carta del 23 de agosto de 1645 } \\
\text { de la Casa de la Contratación }\end{array}$ \\
\hline Su Majestad & 430401104 & 293006662 \\
\hline Particulares & 393883200 & 288886304 \\
\hline Total & 824284304 & 581892966
\end{tabular}

Entonces la diferencia se puede explicar por los gastos realizados entre las dos fechas (salario de la tripulación y fondos destinados a obras pías) o por los errores de cálculo en la suma de los inventarios por buque. En efecto, parece poco probable la explicación del contrabando, porque se trataría entonces de un delito de robo y crimen de lesa-Majestad ${ }^{5}$. Queda sin embargo una diferencia enorme entre

54. Ibíd.: 67-69.

55. Díez de la Calle, 1645, f. 28v. «Generales que se hallan de las flotas de a Nueva España, desde el año de 1581 hasta el de 1645»

56. BNE, Ms 3010, ff. 190r.-193V., Relación de lo que monta la plata, oro y reales que para su Majestad y particulares se ha traído de las Indias en las Armadas y Flotas que han llegado a estos reinos desde el año de 1621 hasta el de 1645 en esta manera.

57. Archivo General de Indias (AGI), Contratación, legajo 5.176: «Con esta enviamos a V magd las relaciones y sumarios generales del oro y plata y reales que se han traído registrados en las naos capitana y almiranta de la flota general don Martin Carlos de Mencos por las cuales parece q lo q viene para v magd por cuenta de su real hacienda monta 228.933.968 mrs y por la de la santa cruzada $54.464 .152 \mathrm{mrs}$ y por la de particulares y otras diferentes cuentas y consignaciones $293.006 .662 \mathrm{mrs}$ y todo monta 581.892.966 mrs que hacen 1.551.714 mrs ducados de a $375 \mathrm{mrs} . »$

58. MORINEAU, 1984: 63 . 
las dos cantidades que deja perplejo ante la capacidad de la Corona para conocer exactamente el importe de las llegadas y para luchar contra el fraude. La Casa de la Contratación era muy consciente de estos problemas que subraya en una carta a Felipe IV con fecha del II de enero de I645 5 :

«Señor. En este punto llegó el gentilhombre del general don jerónimo Gómez de Sandoval en que nos remite la relación inclusa de la cantidad que viene para Vuestra Majestad y particulares en la armada y aunque suele haber en estas relaciones muy grandes variaciones y bajas nos ha parecido remitir a Vuestra Majestad para que lo tenga entendido y que quedamos con muy gran cuidado de sacar las relaciones por los registros y cartas» ${ }^{60}$.

Esto no impide que, en I646, en el Memorial y Noticias Sacras y Reales, al final del capítulo referente a la audiencia de Nueva Galicia, Díez de la Calle proponga una totalidad de las llegadas de metales preciosos desde el principio del reinado de Felipe IV:

«Estos mismos géneros de hacienda, y otros hay en las demás Provincias de las Indias, de que se componen los crecidos tesoros que traen las Flotas y Galeones en que la Majestad divina de Dios N. Señor ha andado tan liberal con nuestro Católico Monarca don Felipe IV que en su glorioso Reinado han llegado en salvo, registrados suyos y de sus vasallos, en sus Reales Armadas de la guarda de la Carrera de Indias, Flotas de la Nueva España, y Tierra Firme, hasta la última que llegó en Agosto de 1645 y Galeones de 25 de enero de 1646, 119 millones 32638 ducados. Destos y de las numerosas rentas destos Reinos ha gastado y gasta Su Majestad liberalísimamente en el aumento de nuestra Santa Fe, y dilatación del Santo Evangelio, como obediente hijo, y defensor de la Santa Iglesia Católica Apostólica Romana, en ellos, y en las Indias, donde al presente sustenta gran número de Religiosos para la reducción, cataclismo, y enseñanza de los naturales de muy dilatados, extendidos y nuevos Reinos» ${ }^{61}$.

\section{En I589, José de Acosta afirmaba ya en su Historia natural y moral de las Indias:}

«La suma de oro que se trae de Indias no se puede bien tazar, pero puedese bien afirmar que es harto mayor que la que refiere Plinio haberse llevado de España a Roma cada año. En la flota que yo vine el año de ochenta y siete, fue la relación de Tierrafirme, doce cajones de oro que por lo menos se da cajón cuatro arrobas, y de Nueva España mil y ciento cien cuenta y seis marcos de oro» ${ }^{62}$.

Este juego de las totalidades es frecuente entre los celadores de la Monarquía católica como León Pinelo que, en su Paraíso en el Nuevo Mundo (I656), habla de una

59. Doy las gracias a Juan Manuel Díaz Blanco por sus explicaciones y por haberme entregado las cartas de la Casa de la Contratación. Para una aclaración de los organismos rectores de la Carrera de Indias, véase Díaz BLANCO, 2012: 34-44.

6o. AGI, Contratación, leg. 5.176, Carta de la Casa de la Contratación a Felipe IV, Sevilla, 11 de enero de 1645.

61. Díez de la CALLe, 1646, f. 112 r.

62. ACOSTA, 2002: 217 . 
suma de 3.240.000.00o pesos de a ocho, que corresponde a un camino cubierto de lingotes de cuatro dedos de grueso y I4 varas de anchura entre las Indias y España ${ }^{63}$.

El cronista de Castilla Gil González Dávila afirma en i623:

«(...) pone asombro considerar de espacio la inmensidad de riquezas que han venido de aquel Orbe a nuestra Nueva España, que pasan, conforme a un memorial que yo vi, de 1500 millones de oro y plata hasta el año de 1617 con registro, sin los que se han sacado de las venas, sin esta razón. Y consta, que solo el cerro de Potosí, se han sacado de las venas de su cuerpo, desde el año 1545, doscientos y sesenta millones de plata» ${ }^{64}$.

Juan Solórzano de Pereira que recupera esta cifra no duda en compararla con cosas incomparables:

«De lo cual y otras cosas, que va añadiendo de estas portentosas riquezas, viene a referir, que las tiene por mayores, que las que gozaron los Romanos, con ser tan encarecidas por Justo Lipsio, y que las de el Rey de China, de quien se dice le tributan sus vasallos treinta y seis millones cada año» ${ }^{65}$.

CUADRO 2: DIFERENTES ESTIMACIONES DE LOS METALES

PRECIOSOS AMERICANOS IMPORTADOS A ESPAÑA ${ }^{66}$ :

\begin{tabular}{lccccc} 
Autores & Periodo & Años & $\begin{array}{c}\text { Pesos de a ocho } \\
\text { reales }\end{array}$ & $\begin{array}{c}\text { Media anual en } \\
\text { pesos }\end{array}$ \\
$\begin{array}{l}\text { Gil González \& } \\
\text { Solórzano Pereira }\end{array}$ & $1492-1617$ & 125 & 1.500 .000 .000 & 12.000 .000 \\
\hline Antonio de León Pinelo & $1492-1656$ & 164 & 3.240 .000 .000 & 19.756 .098 \\
\hline Juan Díez de la Calle & $1621-1648$ & 27 & 166.532 .491 & 6.167 .870
\end{tabular}

No obstante, estas riquezas maravillosas alimentan la crítica antiespañola con la explotación de la mano de obra india y una justificación se impone. Estriba, por una parte, en la idea de intercambios financieros y culturales y, por otra parte, en una forma de crítica oculta de los competidores (nuestros enemigos no actúan mejor...). En el capítulo que dedica a Potosí Díez de la Calle expone así el principio de una especia de pacto colonial:

«Y aunque es aquí que han venido a España tantos millones, también es sin duda que de España han ido a las Indias en diferentes géneros y especies más de 2.000 millones (...).

También es sin duda que demás de la fe y policía que se les llevó y de que carecían que

63. Citado por Bernal Rodríguez, 2005: 294.

64. GONZÁlEZZ DÁVILA, 2003 [1623]: 472

65. Solórzano Pereira, 1648: 424.

66. Cuadro sacado y completado de Bernal Rodríguez, 2005: 295. 
es lo más que le encamino la Majestad Divina por medios de la nación española se les ha llevado las artes, ciencias, bastimentos, telas, frutos y frutas, caballos, bueyes, carneros, cabras y gallinas, y volatería, granos, vino, aceita (...) $)^{67}$.

Todas esas cifras, esas estimaciones y esas enumeraciones demuestran el deseo de apoderarse, en conjunto, de las riquezas de la Corona: esta preocupación concreta y apremiante de poder responder a los acreedores de la Corona, con las relaciones de la Casa de la Contratación, lleva finalmente a hacer el elogio de los sacrificios financieros otorgados por la Corona para la Evangelización. De esto, sin embargo, no resulta un balance coste/beneficios, sino una constelación de cifras en épocas diversas para lugares diferentes. De nuevo son motivos políticos que llevan a Díez de la Calle a interesarse por el coste de las Filipinas.

\section{CIFRAS AL SERVICIO DEL IMPERIO: EL CASO DE LAS FILIPINAS}

El tema de la Hacienda real en Filipinas se conoce bien gracias a la obra de Luis Alonso Álvarez ${ }^{68}$. Nosotros vamos a interesarnos por las fuentes y por los discursos de Díez de la Calle en los años i620-I640: en efecto, las islas Filipinas, más que otra provincia de la Monarquía, son objeto de discursos, basados en cálculos y el coste del imperio, con el objetivo final de promover la generosidad de la Corona.

En manos de Díez de la Calle, se hallan los Sucesos de Filipinas (I609) del oidor Antonio de Morga, las memorias de los procuradores generales de Filipinas, Hernando de los Ríos Coronel (I62I) y Juan Grau y Monfalcón (I637), una relación de la Real contaduría de cuentas (I626). De estos dos últimos documentos, Díez de la Calle se permite reproducir más o menos completamente los datos cuantitativos en su Memorial de $1646^{69}$. Además, las informaciones que saca frecuentemente aquí y allí con fechas diferentes dan una visión bastante confusa de la situación financiera en Filipinas.

En particular, debido al «socorro de la Nueva España» enviado cada año a Filipinas a partir de fondos sacados de la caja de Acapulco, nació y persistió la idea que Manila vivía bajo perfusión del virreinato de Nueva España ${ }^{70}$. Díez de la Calle se hace eco de este tópico, que se verificó algunas veces con los numerosos ataques de los holandeses que sufrió Manila durante la guerra de Treinta años. Díez de la Calle podía leer así en los Sucesos de Filipinas de Antonio de Morga como:

«tiene su Majestad en las Filipinas cada año ciento y cincuenta mil pesos, poco más o menos, fuera de los cuales, todos los años, por no basta resto para los gastos que se hacen, se envía de la caja real de la Nueva España a la de las Filipinas un socorro en dineros (...)».

\footnotetext{
67. BNE, Ms 3024, f. 267.

68. Alonso Álvarez, 2009.

69. Díez de la CALLE, 1646, f. 182

70. Alonso Álvarez, 2009: 261-302.
} 
A propósito de la Caja real de Manila, Morga añade:

«De suerte que siendo el caudal que Su Majestad tiene en estas Islas tan limitado y los gastos tan grandes, la caja real anda alcanzada y se pasa estrecheza y necesidad. (...) De manera que hasta ahora el Rey Nuestro Señor no tiene aprovechamiento de hacienda alguna en las Filipinas, sino gasto no pequeño de la que tiene en la Nueva España, y sólo las sustenta la cristiandad y conversión de los naturales y por las esperanzas de mayores frutos en otros reinos y provincias de la Asia» ${ }^{71}$.

Sin embargo, Díez de la Calle podía oír opiniones divergentes: Hernando de los Ríos Coronel, preocupado por conservar Filipinas en el seno hispánico cuando algunos proyectos sugerían al rey que los cambiase con Portugal contra Brasil, entrega datos cifrados para demostrar la viabilidad financiera del archipiélago asiático ${ }^{72}$. Explica que es la guerra, en particular las expediciones para recuperar las Malucas, la que pesa sobre las finanzas reales: según los documentos de la Real Hacienda de que dispone, los ingresos ascienden en I62I a 255.54I pesos, cuando la Corona ha gastado 218.372 pesos para las Malucas.

No obstante, el oficial madrileño en sus Noticias Sacras y Reales señala particularmente dos documentos: una relación de los oficiales del archipiélago del 20 de julio de 1626 y un memorial del procurador de la ciudad de Manila, Grau y Monfalcón con fecha de i637. Documentos que copió con el título «Lo que cuestan a su Majestad cada año las islas Filipinas» y que publicó en sus obras.

La relación establecida "por certificación de los oficiales reales de ellas del 20 de julio de I626», afirma que, por una parte, los distintos gastos en puestos civiles y eclesiásticos ascienden a 578.989 pesos de oro, además de los 150.000 pesos para la armada y, por otra parte, que las entradas en tributos y tasas son de I86.330 peos: ¡el lucro cesante del rey es de 542.659 pesos! La situación real de los años i620 es en efecto muy difícil. ¿Se puede sospechar que Díez dela Calle haya seleccionado un año particularmente desastroso con el fin de subrayar el compromiso de la Corona en sus confines asiáticos?

Con el segundo, Grau admite que la conservación de Filipinas es fuente de gastos para la monarquía, imputa esto primero a la distancia, luego a la guerra y por fin a la huida del dinero americano hacia Asia:

«Representando por motivos de esta resolución, que aquellas islas no solo no acrecientan las rentas reales, sino que menoscaian y disminuyen, y son una continua causa de gastos ociosos y grandes por ser tantas y tan remotas y de tan difícil conservación. (...) Y para sustentarlas era forzoso que el modo con que España les gobernaba era muy penoso y perjudicial para la monarquía, y sin esperanza de poderle mejorar por ser tanta la plata que con esta ocasión salía de las Indias para ellas, así para los gastos ordinarios de la guerra, como para la conservación del comercio, la cual toda pasaba a la Asia donde nunca salía»73.

71. MORGA, 2007: 294-295.

72. Ríos CORONEL, 1621 .

73. Grau y Monfalcón, 1885: 371. 
Defiende la conservación de Filipinas con dos argumentos: la evangelización de las poblaciones locales y el papel estratégico del archipiélago para conservar otros territorios frente a la potencia holandesa. El oficial se hace caso del balance financiero establecido por Grau y Monfalcón: afirma en particular que el rey ha pagado un salario a $« 5.878$ personas españolas, indias, y de otras naciones» ${ }^{44}$ por 850.734 pesos; como las entradas son de 573.922 pesos, el rey gasta 276.5I2 pesos para Filipinas. Las cifras son colosales y la inversión enorme ${ }^{75}$.

En conclusión, en esas islas los costes son más elevados que las ganancias, y esta sencilla comprobación ha originado una copla providencialista:

"Que por la conversión de un alma de las que habían hallado, daría todos los tesoros de las Indias. Y cuando no bastaran a aquellos daría todo lo que España le rendía de bonísima gana; y que por ningún acontecimiento había de desamparar y dejar de enviar predicadores y ministros que diesen los del Santo Evangelio a todos; y cuantas Provincias se fuesen descubriendo por muy pobres que fuesen y muy incultas y estériles (...)»>76.

Idea que desarrolla unos años más tarde, en el manuscrito de las Noticias Sacras $y$ Reales:

«(...) se han convertido en ellas más de un millón de hombres a nuestra santa fe católica con tantos gastos de la corona real y poco provecho de ella que cada religioso que se envía puesto en Manila cuesta mil ducados y solo Su Majestad que Dios guarde había gastado hasta el año de 642.170.000 ducados en conducirlos para que se empleen en la reducción e instrucción de los naturales (...)»77.

El oficial del Consejo de Indias reproduce las cifras y conclusiones. No obstante, el tema de los recursos financieros de la Corona es particularmente sensible en un periodo difícil para la monarquía.

El ejemplo de Filipinas demuestra que la idea de hacer un balance coste/beneficio para un territorio es factible, pero cada uno puede presentar cifras diferentes ya que existen grandes variaciones de un año, para otro. Este juego de cifras puede servir así discursos diferentes: Hernando de los Ríos Coronel no omite tampoco recordar las riquezas acumuladas con el comercio asiático vía Manila. En efecto, Filipinas generaban, con el Galeón de Manila, ganancias indirectas recaudadas por la caja de Acapulco a la altura de 125.000 pesos al año ${ }^{78}$. Ingresos notorios que no toma en cuenta Díez de la Calle.

74. Copia manuscrita del balance de Grau, BNE, Ms 3010, f. 186r.-188v.; síntesis recuperada y publicada en DíEZ de la CALLe, 1646, f. 182.

75. Si se tiene en cuenta que esas cantidades incluyen los empleos eclesiásticos, las comparaciones están falseadas. No obstante, si consideramos las cifras de la relación de 1626 y las de León Pinelo, las Filipinas representa $16 \%$ de la «masa salarial».

76. BNE, Ms 3010, f. $187 \mathrm{~V}$

77. BNE, Ms, 3023 , f. 338

78. GIRÁLDEZ, 1999: 105 
En conclusión, el objeto de nuestra investigación ha sido de demostrar que el tema clásico de los tesoros americanos se puede también estudiar desde las representaciones de los actores de la época. En efecto, es a partir de las informaciones de que disponían y de su comprensión del espacio y del funcionamiento de la monarquía, que esos actores tomaban decisiones. En este sentido, dependían mucho ( $y$ creo que eran bien consciente de esto) de los acontecimientos, de la incertidumbre, de la distancia-tiempo y de la limitada circulación de informaciones. Si existe realmente la posibilidad y el deseo de hacer un «balance en el sentido de cálculo general de los ingresos y de los gastos de un territorio por un año»79 las informaciones de que dispone el Consejo de Indias aparecen parcelarias, heterogéneas, incluso a veces contradictorias. Al final no se desprende una visión general, porque la contamina rápidamente un discurso imperial y providencialista impregnado de hiperbolismo, de exageración y por lo tanto imprecisiones. Este aspecto central nos recuerda que por más que manipulen las cifras los hombres del siglo XVII, la política y la religión ocupan un papel primordial cuando se trata de pensar lo que todavía no se llamaba el Estado.

79. LEGAY, $2010: 5$. 


\section{BIBLIOGRAFÍA}

Acosta, José de, Historial natural y moral de las Indias, Madrid, Dastin, 2002.

Alonso Álvarez, Luis, El costo del imperio asiático: la formación colonial de las islas Filipinas bajo dominio español, 1565-I800, México, Instituto Mora, 2009.

Álvarez Nogal, Carlos, Los banqueros de Felipe IV y los metales preciosos americanos: I62II665, Madrid, Banco de España, I997.

Álvarez Nogal, Carlos, «Las remesas americanas en las finanzas de la Real Hacienda: la cuantificación del dinero de la Corona (I62I-I675)», Revista de Historia Económica. Journal of Iberian and Latin American Economic History, I6/2 (I998): 453-488.

Álvarez Nogal, Carlos, Sevilla y la monarquía hispánica en el siglo XVII: dinero, crédito y privilegios en tiempos de Felipe IV, Sevilla, Ayuntamiento de Sevilla, 2000.

Bernal Rodríguez, Antonio Miguel, España, proyecto inacaba

do: los costes-beneficios del imperio, Madrid, Fundación Carolina, Centro de Estudios Hispánicos e Iberoamericanos, Marcial Pons Historia, 2005.

BRENDECKE, Arndt, Imperio e información: funciones del saber en el dominio colonial español, Madrid, Iberoamericana, 2012.

Berthe, Jean-Pierre \& CALvo, Thomas (eds.), Administración e imperio: el peso de la monarquía hispana en sus indias (I63I-I648), Zamora, El Colegio de Michoacán, 2011.

Desrosières, Alain, La politique des grands nombres: histoire de la raison statistique, Paris, La Découverte, 2010.

DíAz Blanco, José Manuel, Así trocaste tu gloria: guerra y comercio colonial en la España del siglo XVII, Valladolid, Instituto Universitario de Historia Simancas, 20 I2.

Díez de la CAlle, Juan, Memorial informatorio al Rey... En manos del señor Iuan Baptista Saenz Nauarrete... Contiene lo que Su Magestad prouee en su Cōsejo, y Iunta, y por las dos secretarias de la Nueua España, y Pirù, eclesiastico, secular, salarios, estipendios, y presidios, su gente, y costa, y de que cajas, y hazienda real se paga: valor de las encomiendas de Indios, y otras cosas curiosas, $y$ necessarias, Madrid, $\mathrm{I} 645$.

Díez de la CALle, Juan, Memorial y noticias sacras y reales del imperio de las Indias Occidentales al... Rey... D. Felipe IV...: comprehende lo eclesiástico, secular, político y militar, que por su Secretaria de la Nueva España se provee ..., Madrid, s.n., I646.

Díez de la CAlle, Juan, Memorial y compendio breve del libro intitulado Noticias sacras y reales de los dos imperios de la Nueva España, el Perú y sus islas de las Indias occidentales... Comprehende algunos de los muchos milagros, apariciones, y cosas notables, que sucedieron en la introducción de nuestra santa fe en aquellos imperios, sus grandes conversiones: y lo eclesiástico, y secular, que por las dos secretarias de la Nueva España, y el Perú se provee, presidios, gente, y costa, encomiendas de indios, y otras cosas necesarias, y dignas de saberse, para la verdad, y autoridad de la historia, Madrid, I648.

Dubet, Anne, «Espagne», en Marie-Laure Legay (Ed.), Dictionnaire historique de la comptabilité publique: vers 1500-vers I850, Rennes, Presses universitaires de Rennes, 2010 : 187-204.

García Hernán, Enrique, Consejero de ambos mundos: vida y obra de Juan de Solórzano Pereira (1575-I655), Madrid, Fundación Cultural Mapfre Vida, 2007.

Gaudin, Guillaume, Penser et gouverner le Nouveau Monde au XVII siècle. L'empire de papier de Juan Diez de la Calle, commis du Conseil des Indes, Paris, L'Harmattan, 2013.

Giráldez, Arturo, Born with a Silver Spoon: China, American Silver and Global Markets during the Early Modern Period, tesis doctoral, Universiteit van Amsterdam, I999. 
González Dávila, Gil, Teatro de las grandezas de la villa de Madrid, corte de los Reyes Católicos de España, Valladolid, Ed. Maxtor, 2003 [original de I623].

Grau y Monfalcón, Juan, «Memorial Dado Al Rey En Su Real Consejo de Las Indias Por D. Juan Grau y Monfalcón, Procurador General de Las Islas Filipinas, Sobre Las Pretensiones de La Ciudad de Manila Y Demás Islas Del Archipiélago En Su Comercio Con La Nueva España», en Luis Torres Mendoza (ed.), Colección de Documentos Inéditos Relativos Al Descubrimiento, Conquista Y Colonización de Las Posesiones Españolas En América Y Oceanía, Sacados, En Su Mayor Parte, Del Real Archivo de Indias, Madrid, Manuel B. Quirós, I865

Hespanha, António Manuel, Vísperas del Leviatán: instituciones y poder político (Portugal, siglo XVII), Madrid, Taurus, I989.

LegAY, Marie-Laure (ed.), Dictionnaire historique de la comptabilité publique: vers I500-vers I850, Rennes, Presses universitaires de Rennes, 2010.

León PINelo, Antonio de, El gran canciller de las Indias, editado por Guillermo Lohmann Villena, Sevilla, Publicaciones de la Escuela de Estudios Hispano-Americanos, 1953.

MAZín, Oscar, «Catedrales versus órdenes religiosas en Nueva Espana y el Perú: el pleito de los diezmos y la situación agropecuaria a mediados del siglo XVII», en María del Pilar Martínez López-Cano y Francisco Javier Cervantes Bello (coords.), Reformas y resistencias en la Iglesia novohispana, México, UNAM, Benemérita Universidad Autónoma de Puebla, 20I4, p. 20I-225.

Millares Carlo, Agustín, Tres estudios biobibliograficos, Maracaibo, Universidad del Zulia, I96I.

Morga, Antonio De, Sucesos de las islas filipinas, editado por Francisca Perujo, México, Fondo de Cultura Económica, 2007.

MorineaU, Michel, Incroyables gazettes et fabuleux métaux: les retours des trésors américains d'après les gazettes hollandaises $X V I^{\text {èe }}$-XVIII ${ }^{\text {ème }}$ siècles, Londres, Cambridge University Press, Maison des Sciences de l'Homme, I984.

Parker, Geoffrey, La crisis de la monarquía de Felipe IV, Valladolid, Barcelona, Instituto Universitario de Historia Simancas, Universidad de Valladolid-Crítica, 2006.

Ríos CoRonel, Fernando de los, Memorial y relación para su Magestad del Procurador General de las Filipinas, de lo que conviene remediar y de las riquezas que ay en ellas y en las Islas de Maluco, Madrid, viuda de Fernando Correa, I62I.

SÁNCHEZ Bella, Ismael, La Organización financiera de las Indias (siglo XVI), Sevilla, Consejo superior de investigaciones científicas, I968.

Solórzano Pereira, Juan, Política Indiana, Madrid, Diego Díaz de la Carrera, I648

YUn CASALILla, Bartolomé, Marte contra Minerva: el precio del imperio español, c. I450-I60o, Barcelona, Crítica, 2004.

Zavala, Silvio Arturo, El servicio personal de los indios en el Pérú, México, El Colegio de México, I978-1980, 3 vols. 

Monográfico · Special Issue: La construcción de la Hacienda Hispánica (siglos XVII-XIX). El gobierno de la Hacienda / Construction of the $18^{\text {th }}-19^{\text {th }}$ Century Spanish Public Finance System. The Governance of Public Finances

\section{Rafael Torres-Sánchez \& Michel Bertrand \& AnNe Dubet \& Sergio Solbes Ferr}

Introducción / Introduction

\section{Anne Dubet}

La suspensión de pagos de 1739: juna medida de «buen gobierno» de la Hacienda? / The Suspension of Payments of 1739: A Measure of «Good Governance» of Royal Finances?

\section{7}

\section{José Miguel Delgado BarRado}

Entre Reyes y Ministros de Hacienda. Bernardo Francisco Aznar y e «nodo 1732» / Between Kings and Ministers of Finance. Bernardo Francisco Aznar and the «1732 Node»

\section{5}

\section{ANA Ma Coll Coll}

La gestión de la Hacienda en un territorio in medio mari: la Intendencia de Mallorca en el siglo XVIII / The Public Finances Management in a Territory in Medio Mari: The Intendancy of Majorca in the Eighteenth Century

\section{Guillaume Gaudin}

Cifras al servicio de la grandeza del Rey Católico. Las finanzas del Imperio vistas desde el Consejo de Indias a mediados del siglo XVII / Figures in the Service of the Greatness of the Catholic King. The Finances of the Empire Seen from the Council of the Indies in the Middle of the Seventeenth Century

135 Roberta Giannubilo StumpF

Las reformas para la fiscalización de los funcionarios de la Hacienda portuguesa en Ultramar en la segunda mitad del XVIII / The Reforms of the Inspection of the Officials within the Portuguese Treasury Overseas in the Second Half of the $18^{\text {th }}$ Century

163 Marie-Laure Legay

El gobierno de la Hacienda y la cuestión monetaria en los Países Bajos españoles y austriacos (Siglos XVI-XVIII) / The Government of Finances and the Currency in Spanish and Austrian Netherlands (16 $6^{\text {th }}-18^{\text {th }}$ Centuries)

\section{Miscelánea · Miscellany}

\section{EnRIQUe Milán Coronado}

Controlar y reformar: la visita al consejo de hacienda de Lope de los Ríos (1664-1667) / Control and Reform: The Visit to Lope de los Ríos' the Finances Council (1664-1667)

\section{Francisco josé García Pérez}

La resistencia a la clausura en los monasterios femeninos de Mallorca durante el siglo XVIII / The Resistance to the Enclosure in the Feminine Monasteries of Majorca during the XVIII ${ }^{\text {th }}$ Century

\section{VÍCTOR ECHARRI IRIBARREN}

El proyecto del ingeniero Carlos Robelin para las fortificaciones de Puebla de Sanabria en 1722 / Engineer Carlos Robelin's Project for the Fortifications of Puebla de Sanabria in 1722

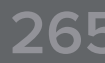

Francisco Valverde Fernández

El patrimonio municipal de Torrefranca y Torremilano, hoy Dos Torres (Córdoba), en la Edad Moderna / The Municipal Patrimony of Torrefranca and Torremilano, Nowadays Dos Torres, in the Modern Age

\section{Antoni Picazo Muntaner}

Las judaizantes del Reino de Mallorca. La resistencia religiosa de las chuetas en el siglo XVII / The Judaists of the Kingdom of Mallorca: The Religious Resistance in the Seventeenth Century

307 Ana María Parrilla Albuerne y Jesús Héctor Trejo Huerta Pedro Quesada, del campo de batalla a la burocracia americana: un ejemplo de versatilidad (1784-1833) / Pedro Quesada, from the Battlefield to the American Burocracy: An Example of Versatility (1784-1833)

\section{José Javier Rodríguez Solís}

La Monarquía de España desde Castilla. Identidad y reinos en la obra de Pedro Salazar de Mendoza / The Monarchy of Spain from Castile. Identity and Kingdoms in Pedro Salazar de Mendoza's Work

\section{Taller de historiografía $\cdot$ Historiography Workshop}

\section{Ensayos · Essays}

\section{IsABEl LoBato Franco}

Cataluña en la Carrera de Indias, treinta y cinco años después. Lo que queda por hacer / Cataluña en la Carrera de Indias, Thirty Five Years Later. What Remanis to Be Done

\section{Reseñas • Book Review}

379 Torremocha Hernández, Margarita y Corada Alonso, Alberto (eds.), La mujer en la balanza de la justicia. (Castilla y Portugal, siglos XVII y XVIII) (Rocío MARTÍNEZ LóPEZ)

385 Valladares, Rafael (ed.), El mundo de un valido. Don Luis de Haro y su entorno, 1643-1661 (IMANOL MERINo MALILLOS)

393 Angulo Morales, Alberto y Aragón Ruano, Álvaro (eds.), Recuperando el Norte. Empresas, capitales y proyectos atlánticos en la economía imperial hispánica (Sergio GutiérRez Cantero)

1.1 García Hurtado, Manuel-Reyes (ed.), El Siglo XVIII en femenino. Las mujeres en el Siglo de las Luces (MARía RuIz ORTIz)

1.3 Fragoso, João \& Gonçalo Monteiro, Nuno (organizadores), Um reino e suas repúblicas no atlántico. Comunicações políticas entre Portugal, Brasil e Angola nos séculos XVII e XVIII (Francisco Precioso IzQUIERDo)

1.7 Ribot, Luis \& Iñurritegui, José Ma (eds.), Europa y los tratados de reparto de la Monarquía de España, 1668-1700 (AITOR DíAz PAREDES)

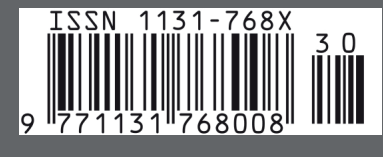

